\title{
Microphone-Array Measurements in a Cryogenic Wind Tunnel
}

\author{
Thomas Ahlefeldt* and Lars Koopı \\ DLR, German Aerospace Research Center, D-37073 Göttingen, Germany
}

DOI: $\underline{10.2514 / 1 . J 050083}$

\begin{abstract}
Based on previous studies with microphones and electronic equipment in a cryogenic environment, a test array for cryogenic application has been developed. Electret microphones, electronic equipment, and fairing material have been successfully tested by the authors under cryogenic conditions and have demonstrated long-term stability. Subsequently, acoustic array measurements performed in a cryogenic wind tunnel for various temperatures in the range of 100 to $300 \mathrm{~K}$, using a single-rod configuration, are described in this paper. The Mach number was in the range 0.1 to 0.3 , and the Reynolds number (based on the cylinder diameter of $2.5 \mathrm{~mm}$ ) was in the range of $5 \cdot 10^{3}$ to $8 \cdot 10^{4}$. The experiments demonstrated the technical feasibility of performing aeroacoustic array measurements at these low temperatures. A systematic study of Reynolds- and Mach-number effects on the radiated noise of a singlerod configuration has been conducted. The results showed good agreement between theory and measured sound radiation. A Reynolds number dependency of the measured and predicted sound power can be shown.
\end{abstract}

\section{Nomenclature}

$C_{l^{\prime}} \quad=$

$c_{0} \quad=\quad$ speed of sound $\mathrm{m} \cdot \mathrm{s}^{-1}$

$d \quad=$ rod diameter, $\mathrm{mm}$

$\mathbf{e}=$ phase shift vector

$f \quad=$ frequency, $\mathrm{Hz}$

$j \quad=$ imaginary unit

$l=$ rod length, $\mathrm{mm}$

$M a=$ Mach number

$m_{\text {mol }}=$ molar mass, $\mathrm{kg} \cdot \mathrm{mol}^{-1}$

$n_{\text {mic }}=$ number of microphones

$P \quad=$ sound power, $\mathrm{W}$

$p \quad=$ sound pressure, $\mathrm{Pa}$

$p_{\text {rms }}=$ rms value of the sound pressure, $\mathrm{Pa}$

$p_{\text {stat }}=$ static pressure, $\mathrm{Pa}$

$\hat{Q}^{2}=$ source strength, $\mathrm{kg} \cdot \mathrm{s}^{-2}$

$\mathcal{R}=$ molar gas constant, $=8.314472 \mathrm{~J} \cdot \mathrm{mol}^{-1} \cdot \mathrm{K}^{-1}$

$r=$ distance, $\mathrm{m}$

$R e_{d}=$ Reynolds number based on diameter $d$

$\mathbf{R}_{D R}=$ cross-correlation matrix with diagonal term set to zero, $\mathrm{Pa}^{2}$

$S=$ surface area, $\mathrm{m}^{2}$

$\hat{S}_{z z}=$ beamformer output, $\mathrm{Pa}^{2}$

$\mathrm{SPL}=$ sound power level in reference to $1 \cdot 10^{-12} \mathrm{~W}, \mathrm{~dB}$

St $=$ Strouhal number

$T=$ temperature, $\mathrm{K}$

$u_{\infty}=$ freestream velocity, $\mathrm{m} \cdot \mathrm{s}^{-1}$

$x, y=$ position, $\mathrm{m}$

$\mathbf{y}_{\mathbf{f}}=$ scan location vector

$\gamma=$ adiabatic index

$\theta=$ angle normal to the flow direction, ${ }^{\circ}$

$\Lambda_{d}=$ correlation length normalized by cylinder diameter

$\mu=$ dynamic viscosity, $\mathrm{kg} \cdot \mathrm{m}^{-1} \cdot \mathrm{s}^{-1}$

$\rho \quad=$ density, $\mathrm{kg} \cdot \mathrm{m}^{-3}$

$\omega=$ angular frequency, $\mathrm{rad} \cdot \mathrm{s}^{-1}$

Received 22 July 2009; revision received 11 March 2010; accepted for publication 4 April 2010. Copyright $(\underset{2}{2010}$ by Thomas Ahlefeldt and Lars Koop. Published by the American Institute of Aeronautics and Astronautics, Inc., with permission. Copies of this paper may be made for personal or internal use, on condition that the copier pay the $\$ 10.00$ per-copy fee to the Copyright Clearance Center, Inc., 222 Rosewood Drive, Danvers, MA 01923; include the code 0001-1452/10 and \$10.00 in correspondence with the CCC.

${ }^{*}$ Research Scientist, Institute of Aerodynamics and Flow Technology, Department of Experimental Methods. Member AIAA.

${ }^{\dagger} \mathrm{Head}$ of the Acoustic Group, Institute of Aerodynamics and Flow Technology, Department of Experimental Methods. Member AIAA.

\section{Superscript}

$\mathcal{H}=$ conjugate transpose

\section{Introduction}

$\mathbf{T}$ HE prediction of full-scale airframe noise based on small-scale model measurements via the phased microphone-array technique is well known and in common practice in closed test sections [1]. Early studies by Hayes et al. [2] showed the importance of Reynolds-number effects on airframe noise. Especially for the case of high-frequency noise, as generated by the flap tip on a high-lift configuration, the results indicated the important role of Reynolds numbers in the aeroacoustic source mechanism.

As remarked by Stoker et al. [3], even pressurized wind tunnels cannot generally achieve full-scale Reynolds numbers. One method to increase the Reynolds number is to perform tests under cryogenic conditions. Consequently, Stoker et al. successfully carried out measurements in a mildly cryogenic pressurized environment as a proof-of-concept effort to evaluate the feasibility of carrying out aeroacoustic measurements in a fully cryogenic environment. At temperatures down to $T=226.5 \mathrm{~K}$, Stoker et al. showed that the equipment could be used in a mildly cryogenic environment and acoustic data could successfully be acquired.

In the present work, a microphone array was constructed to perform measurements in a cryogenic wind tunnel. The microphones were tested at temperatures down to $T=100 \mathrm{~K}$. At these temperatures, significantly increased Reynolds numbers can be achieved. Figure 1 shows the increase in Reynolds number obtained by decreasing the temperature. In this example, the Reynolds number is based on a length scale of $0.24 \mathrm{~m}$. The increase is especially pronounced at lower temperatures.

In the first step, the testing of sensor equipment, such as microphones, electronic devices, cables for signals and power supply, and the material used for the fairing of the array (the plugs, etc.) was conducted. In the second step, a test microphone array was used to study the aerodynamic noise of a cylinder in a homogeneous flow at cryogenic conditions. Finally, the measured data were evaluated.

This paper focuses on the following items.

1) The first item is the test setup for the aeroacoustic measurement with a rod configuration in a cryogenic wind tunnel.

2) The second item is the modifications in the analysis method to account for the cryogenic environment.

3) The third item is a systematic analysis of measured data with respect to Reynolds number dependency.

4) The fourth item is the comparison of the measured data with a semianalytical model.

The wind-tunnel tests with the test microphone array described in the present work were conducted in March 2008 over a period of 


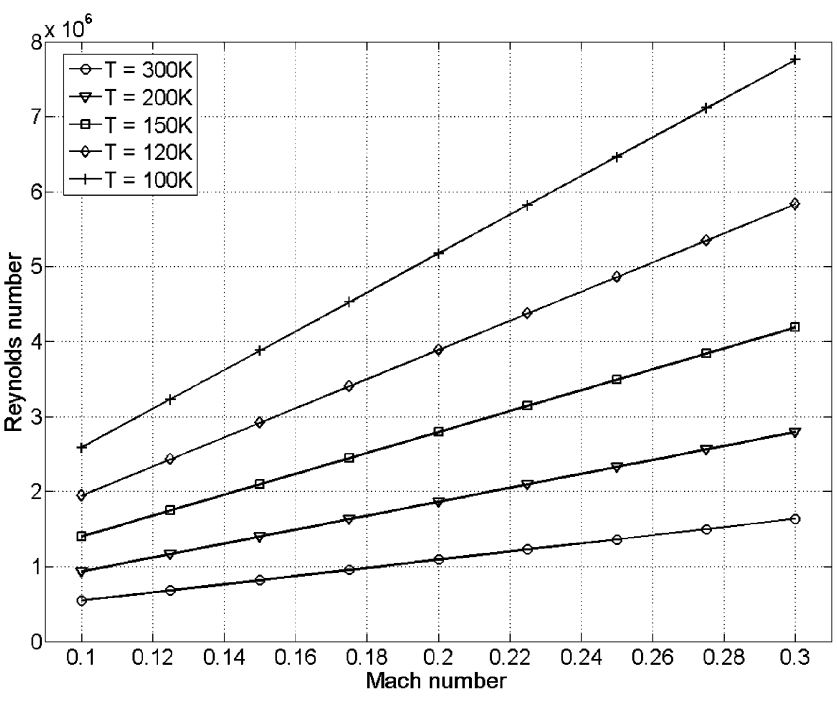

Fig. 1 Reynolds number versus Mach number at various temperatures. The Reynolds number is based on a length scale of $0.24 \mathrm{~m}$.

2 weeks. To our knowledge, this is the first time that aeroacoustic noise data have been acquired under these extreme cryogenic conditions.

\section{Microphone Array}

\section{Measurement Setup}

In the primary step, microphones were tested for use in a cryogenic environment. In previous tests, simple electret microphones, operating as both heated and unheated, were successfully tested at cryogenic temperatures. These microphones, of type RTI Tech 1207A, were used for the measurements carried out in this work.

To ensure the long-term stability of these microphones, preliminary long-term tests were performed under different conditions in the climate chamber of the German-Dutch wind tunnels (DNW) cryogenic wind tunnel located at the DLR Cologne site [Kryo-Kanal Koeln (KKK)] (DNW-KKK). These prior tests were completed successfully; the microphones, preamplifiers, associated equipment, and fairing materials were shown to be capable of surviving cryogenic test conditions at temperatures of $100 \mathrm{~K} \leq T \leq 290 \mathrm{~K}$. It should be noted that no failures occurred until the temperature gradient was increased to above $50 \mathrm{~K}$ per hour. For the electronic devices, cryogenic-capable components were chosen, and the cables were coated with Teflon. Figure 2 shows the microphone with its attached preamplifier and a schematic of the preamplifier circuit.

After completion of the sensor tests, a microphone array suitable for cryogenic testing and consisting of 21 electret microphones was constructed. The fairing of the array was made of aluminum with a thickness of $25 \mathrm{~mm}$. The dimensions of the array were $1700 \mathrm{~mm}$ in the streamwise and $110 \mathrm{~mm}$ in the vertical (normal to the flow) directions. The leading and trailing edges had a slope of $6^{\circ}$ to reduce disturbances due to flow separation. The fairing of the array was mounted onto compressed laminated wood. To allow for contraction of the alloy at lower temperatures, the fairing assembly was rigidly

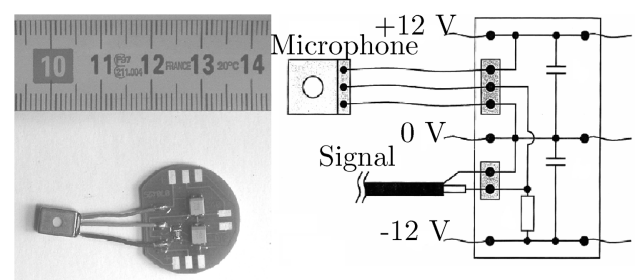

Fig. 2 Photo of the electret microphone and the preamplifier, which had been built in-house (left), and schematic of the preamplifier circuit (right).

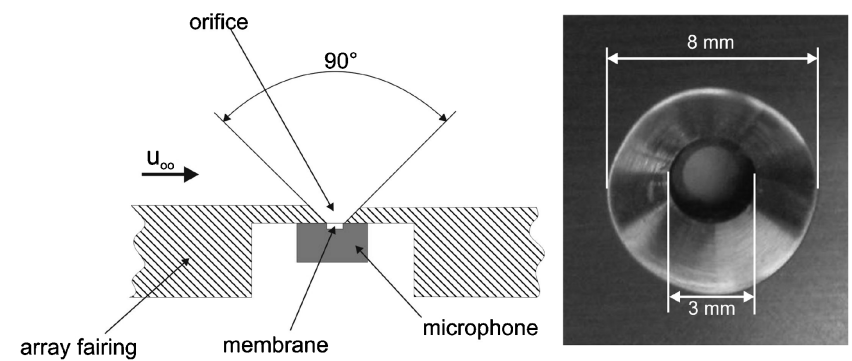

Fig. 3 Detailed view of the microphone mounting in the array fairing. The sketch on the left shows the cross section of the base plate of the array in the region of one microphone. The photo on the right shows the orifice from the top side, which is exposed to the flow [4].

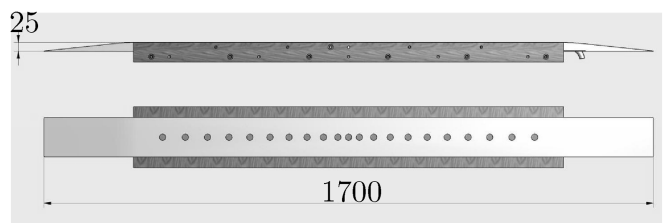

Fig. 4 The microphone array (mounted onto compressed laminated wood) contains 21 microphones (displayed as circles on the lower plot) arranged along a line and spaced at logarithmic distances relative to the center. Dimensions are in $\mathbf{~ m m}$.

fixed only at the center. Figure $\underline{3}$ shows a detailed view of the microphone mounting in the array fairing. The sketch shows the cross section of the base plate of the array in the region of one microphone. The electret microphones were recess mounted to the surface, with the openings having a cone angle of $90^{\circ}$. As described and previously used by Koop and Ehrenfried [4], the basic idea behind this concept is to reduce the influence on the microphone membranes of wall pressure fluctuations caused by the turbulent boundary layer.

The 21 microphones were arranged along a line and spaced at logarithmic distances relative to the central microphone, as depicted in Fig. 4. This arrangement was chosen to get maximum side-lobe suppression in the frequency range between 2 and $20 \mathrm{kHz}$.

The microphones operated with a supply voltage of $12 \mathrm{~V}$. Each data cable was shielded individually. Two separate power supply circuits were used in order to obtain high reliability.

\section{Wind Tunnel}

The measurements were performed at the DNW cryogenic wind tunnel located at the DLR Cologne site (Kryo-Kanal Koeln, DNWKKK). Figure 5 shows a sketch of the wind-tunnel facility. DNW-KKK is a continuous-flow low-speed wind tunnel with a $2.4 \times 2.4 \mathrm{~m}$ closed wall test section. By injecting liquid nitrogen into the flow, the wind tunnel can be operated in the range of $100 \mathrm{~K}<$ $T<300 \mathrm{~K}$ at Mach numbers up to $M a=0.38$. This corresponds to a maximum Reynolds number of $R e_{0.1 \cdot \sqrt{S}}=9.5 \cdot 10^{6}$, based舀 on the cross section $S$. The ratio of the achieved Reynolds number at $100 \mathrm{~K}$ to that of $300 \mathrm{~K}$ is 7.5 for a constant freestream velocity and 4.5 for a constant Mach number. The turbulence level is $\approx 0.1$ to $0.15 \%$ at a temperature of $295 \mathrm{~K}$ and a freestream velocity of $80 \mathrm{~m} / \mathrm{s}$. At lower temperatures, the turbulence level is higher [5]. The restricted access to the test section and the special environmental conditions (very low temperatures) are different than in conventional wind tunnels and must already be considered and allowed for in the planning phase. Furthermore, the material characteristics of the measurement equipment and of the model, which are exposed to the low

\footnotetext{
Data available online at http://www.dnw.aero [retrieved 16 May 2007].

${ }^{\S}$ The adoption of a normalization length of $0.1 \cdot \sqrt{S}$ is in common use for the characterization and comparison of different wind tunnels.
} 


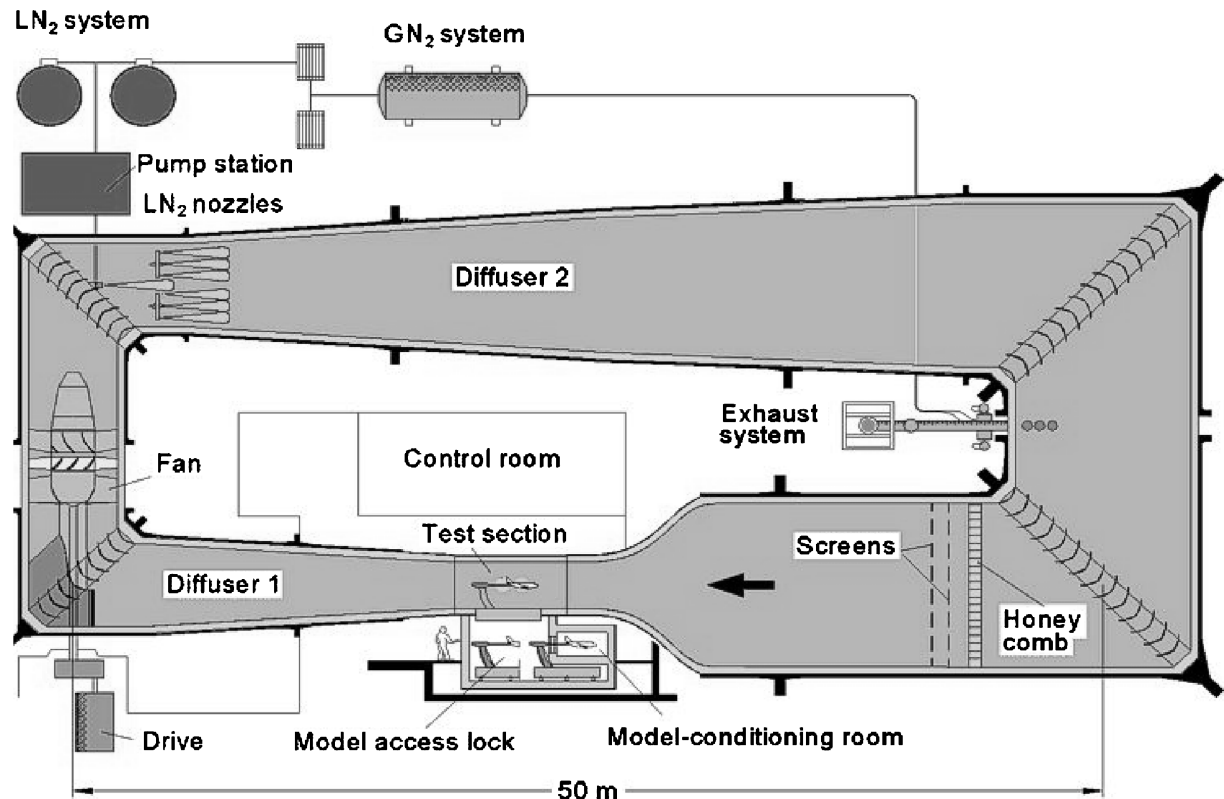

Fig. 5 Sketch of the cryogenic wind tunnel (DNW-KKK) in Cologne.

temperatures, have to be shown to be able to withstand the cryogenic environment.

\section{Measurement Procedure}

For the test setup, a single rod was used as an aeroacoustic noise source; the single rod placed in a homogeneous flow is a well-known test case and is well acknowledged as an aeroacoustic source [6-8] Figures 6 and 7 are showing the test setup. The array is mounted onto the sidewall, and the rod is located in the center of the test section. Figure 7 shows the microphone array and the cylinder in the $(x, z)$ plane.

The rod has a diameter of $d=2.5 \mathrm{~mm}$ and is mounted over the full height of the test section between the floor and ceiling $(2.4 \mathrm{~m})$. To reduce the bending of the rod due to the relatively high flow velocity, the rod is guided trough a small hole of the ceiling. Below the test section floor, a mass of $20 \mathrm{~kg}$ is attached to the rod, preventing the rod at Mach numbers of $M a \leq 0.3$ from bending more than $80 \mathrm{~mm}$ in the center of the test section.

The rod is wrapped with wire of a $1 \mathrm{~mm}$ diameter over most of its length to eliminate coherent structures, with the exception of a length of $171 \mathrm{~mm}$ at about the height of the microphone array, which is left unwrapped to enable these structures.

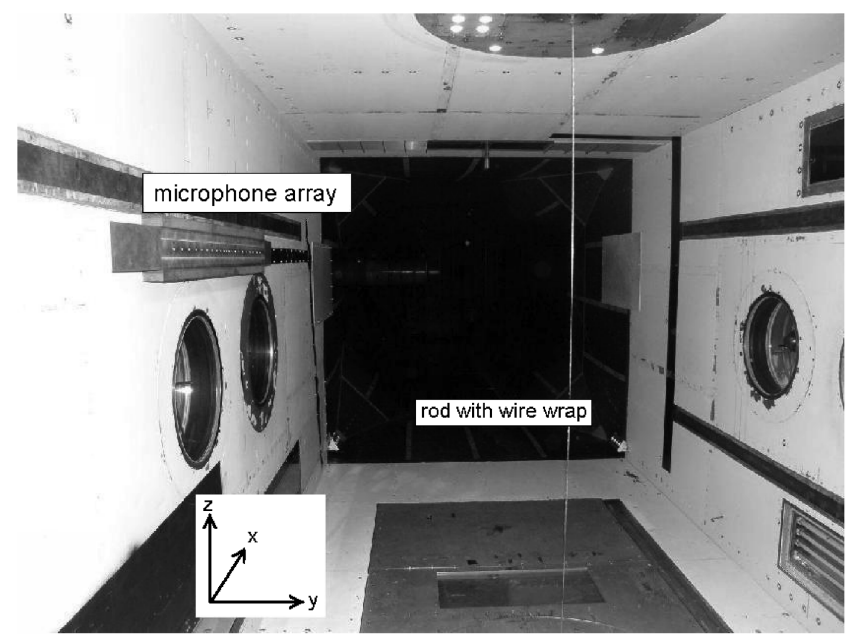

Fig. 6 Photo of the test section with the array mounted on the side wall and the rod situated in the center, view in flow direction.
Measurements were carried out with a wide range of operational flow parameters. The temperature was varied in six steps, in the range of $100 \mathrm{~K}<T<290 \mathrm{~K}$, using pure nitrogen as a test gas for all measurement points. The Mach number was altered in eight steps, in the range of $0.1<M a<0.3$. Each measurement point was reached by approaching the Mach number from below. The range of $R e_{d}$ was $5 \cdot 10^{3}<R e_{d}<8 \cdot 10^{4}$, where $R e_{d}$ is the Reynolds number based on the rod diameter $d=2.5 \mathrm{~mm}$ and the freestream velocity of uniform flow.

As shown in Table 1 , the resulting measurement points at each $M a / T$ combination were measured several times over a period of seven days. The irregular distribution of repeated measurements over the varied parameters is caused by the measurement sequence and the operating efficiency of the wind tunnel. A statistical analysis of the results allows and account to be taken of the possible hysteresis effects, repeatability, and long-term stability.

\section{Data Acquisition and Preprocessing}

Microphone signals were simultaneously sampled with an A/D conversion of 16 bits, at a sampling frequency of $150 \mathrm{kHz}$, by a data acquisition system located outside the test section. The recording time for each measurement was $20 \mathrm{~s}$. To reduce the influence of the low-frequency wind-tunnel noise, a high-pass filter with a cutoff

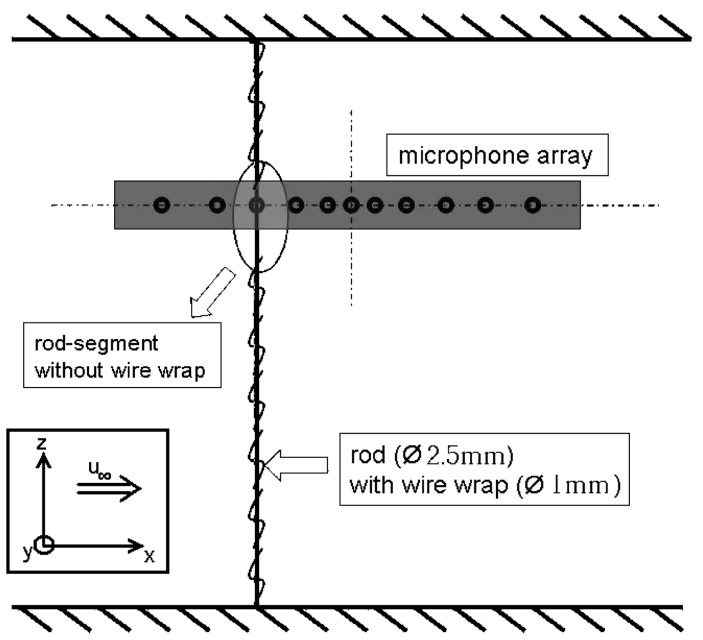

Fig. 7 Drawing of the measurement setup in the $(x, z)$ plane. 
Table 1 Matrix of measurement points. Given is the number of measurements performed at each measurement point

\begin{tabular}{ccccccc}
\hline \hline$M a / T$ & $290 \mathrm{~K}$ & $250 \mathrm{~K}$ & $200 \mathrm{~K}$ & $170 \mathrm{~K}$ & $130 \mathrm{~K}$ & $100 \mathrm{~K}$ \\
\hline 0.1 & 4 & 8 & 12 & 16 & 12 & 12 \\
0.125 & 4 & 8 & 12 & 16 & 12 & 12 \\
0.15 & 4 & 8 & 12 & 16 & 12 & 12 \\
0.175 & 4 & 8 & 12 & 16 & 12 & 10 \\
0.2 & 4 & 8 & 12 & 16 & 12 & 8 \\
0.225 & 4 & 4 & 12 & 16 & 12 & 8 \\
0.25 & 4 & 8 & 12 & 16 & 12 & 8 \\
0.3 & 4 & 0 & 0 & 0 & 12 & 8 \\
\hline \hline
\end{tabular}

frequency of $500 \mathrm{~Hz}$ was used. The measured data were corrected with regard to the filter response, which can be seen in Fig. 8. The data were processed using an overlap of $50 \%$ and a fast-Fouriertransform block size of 4096 samples, with a Hanning window, yielding a narrowband frequency resolution of $36.6 \mathrm{~Hz}$.

\section{Calibration Procedure}

In terms of the frequency response for the individual microphones mounted in the array, a comparative calibration with a $\frac{1}{4}$-in. G.R.A.S. condenser microphone was carried out in a semianechoic chamber before the measurement. As a calibration source, a tweeter in the frequency range of $1 \mathrm{kHz}<f<50 \mathrm{kHz}$ was used. To accommodate the radiation characteristics of the tweeter, the tweeter was traversed in front of the microphone array. The transfer function with respect to this reference microphone, which was calibrated using a sound level calibrator, was measured. The pressure-field reference microphone was mounted in the center of an aluminum plate of the size $1 \times 1 \mathrm{~m}$. It was flush mounted to the surface. Phase matching of the microphones was checked using a cross-correlation analysis, with the tweeter at known positions.

Additionally, the type of electret microphone used in the array was compared with prototype $\frac{1}{4}$-in. Brüel and Kjær cryogenic pressurefield condenser microphones with a known temperature-amplitude response. To this end, two electret microphones were mounted on a plate together with two Brüel and Kjær microphones. The electret microphones were recessed behind a cone in the same way as in the microphone array, and the Brüel and Kjær microphones were flush mounted. The plate was placed into a cryogenic chamber and exposed to the radiated white noise of a tweeter that was cold resistant. The frequency response of the electret microphones was obtained by the average of the obtained transfer functions between the RTI microphones used in the array and the Brüel and Kjær microphones. The amplitude correction was applied to all measured data. Because of smoothing and averaging, the correction curves are assumed to have an uncertainty of $\approx \pm 1.5 \mathrm{~dB}$ for frequencies below $25 \mathrm{kHz}$ and $\approx \pm 3 \mathrm{~dB}$ for higher frequencies. Figure 9 shows the frequency response in decibels for several temperatures. For

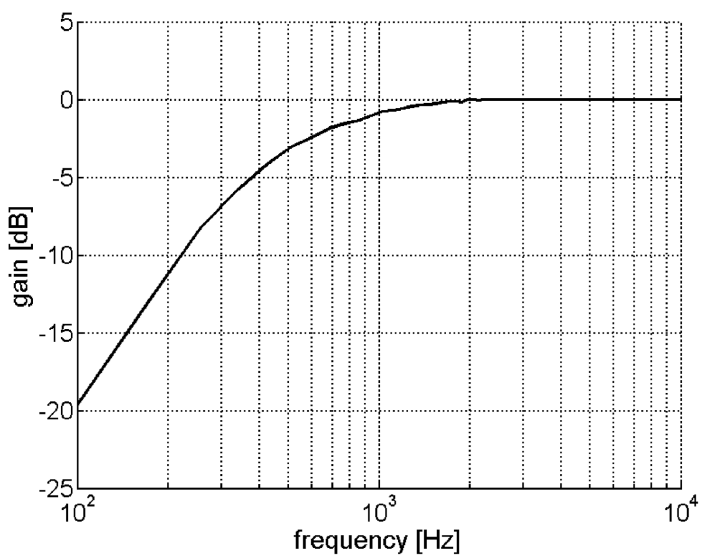

Fig. 8 Attenuation of the $500 \mathrm{~Hz}$ high-pass filter of the data acquisition system. decreased temperatures, an increased frequency dependency can be observed. The shape of the response curves becomes wavy and shows a change in response that goes from -8 to $+11 \mathrm{~dB}$ for a temperature of $100 \mathrm{~K}$.

\section{Beamforming Algorithms}

\section{Basic Gas Relations}

In a (cryogenic) wind tunnel, the state of the gas can be described by the density $\rho$, the speed of sound $c_{0}$, and the dynamic viscosity $\mu$. These quantities depend on temperature $T$. Considering a perfect gas, the density of a gas is described by

$$
\rho=\frac{p_{\text {stat }}}{\mathcal{R} T}
$$

The dynamic viscosity $\mu$, following Sutherland's law [9], can be written as

$$
\mu=\mu_{0} \frac{T_{0}+C}{T+C}\left(\frac{T}{T_{0}}\right)^{3 / 2} \Rightarrow \mu \propto \frac{T^{3 / 2}}{T+C}
$$

In this formulation for nitrogen $\mathrm{N}_{2}$, the constants $C, T_{0}$, and $\mu_{0}$ are defined by $C=111 \mathrm{~K}, T_{0}=300.55 \mathrm{~K}, \quad$ and $\mu_{0}=$ $17.81 \cdot 10^{-6} \mathrm{~Pa} \cdot \mathrm{s}$.

The formulation for the speed of sound can be derived from the ideal gas law:

$$
c_{0}=\sqrt{\frac{\gamma \mathcal{R} T}{m_{\mathrm{mol}}}}
$$

$\mathcal{R}$ denotes the molar gas constant and $m_{\text {mol }}$ the molar mass. Both are constant for pure nitrogen. The slight change of the adiabatic index $\gamma$ by $\Delta \gamma=0.02$ in the examined temperature range from 300 to $100 \mathrm{~K}$ can be obtained from lookup tables [10].

For the description of the prediction model, the following dimensionless quantities are also important: Mach number $M a$, Reynolds number $R e_{d}$, and Strouhal number $S t$, which are defined as $M a:=u_{\infty} / c_{0}, R e_{d}:=\rho u_{\infty} d / \mu$, and $S t:=f d / u_{\infty}$.

\section{Conventional Beamforming}

The array data were processed using conventional beamforming in the frequency domain [11] to obtain the reconstructed source autopowers $\hat{S}_{z z, \exp }$ on a grid at scan locations $\mathbf{y}_{\mathbf{f}}$,

$$
\hat{S}_{z z, \exp }\left(\mathbf{y}_{f}, \omega\right)=\frac{\mathbf{e}\left(\mathbf{y}_{\mathbf{f}}, \omega\right)^{\mathcal{H}} \mathbf{R}_{D R}(\omega) \mathbf{e}\left(\mathbf{y}_{\mathbf{f}}, \omega\right)}{n_{\text {mic }}^{2}-n_{\text {mic }}}
$$

$\mathbf{R}_{D R}$ denotes the cross-correlation matrix of the microphone signals dependent on frequency $\omega$. The subindex $D R$ denotes that the diagonal terms of the cross-correlation matrix $\mathbf{R}$ are set to zero. In this formulation, no weighting is applied to the microphone signals. The number of microphones is denoted by $n_{\text {mic }}$. The phasor $\mathbf{e}$ with $|\mathbf{e}|=1$ describes the relevant phase shift based on the point source assumption under homogeneous flow conditions. The superscript $\mathcal{H}$ denotes the conjugate transpose of the matrix. For the calculation of

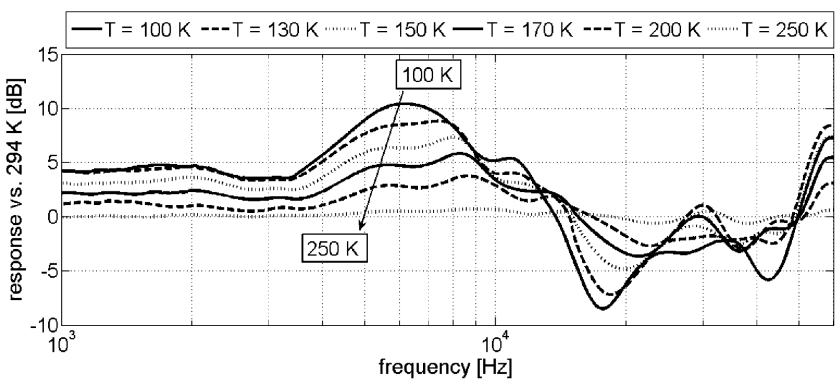

Fig. 9 Frequency response (in $\mathrm{dB}$ ) of the electret microphones used in the microphone array for several temperatures from 100 to $250 \mathrm{~K}$. 


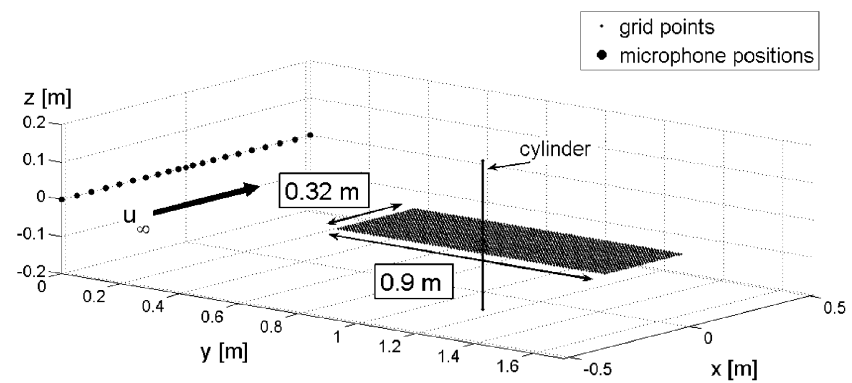

Fig. 10 Grid for the array calculations. The plot also shows the position of the cylinder going through the grid and the microphones. The coordinate system origin is chosen to be at the central array microphone.

the relevant phase shift, the change in speed of sound for different temperatures has to be considered.

The array output is calculated on a discrete grid with equidistant grid points $\mathbf{y}_{f}$. The grid covers the region of interest in an observation plane at the height $z$ of the microphone array (where the cylinder is not wrapped). The grid used in the present study can be seen in Fig. 10. The observation plane is perpendicular to the cylinder axis and has a resolution of $\delta x=\delta y=10 \mathrm{~mm}$.

Considering the linear aperture of the array, no spatial resolution can be given for varying values of $z$. To give an illustration, Fig. 11 shows the point-spread function of the microphone array for three different frequencies and compares them for temperatures of 290 and $100 \mathrm{~K}$. This function describes the map that is produced by a single point source, which has unit strength, and gives information about the spatial resolution and the main-to-side-lobe ratio of the microphone array. The position of the point source is, in this case, $(x, y, z)=(0.17,1.15,0 \mathrm{~m})$, which is situated at the assumed cylinder position. In general, the results at frequencies up to $20 \mathrm{kHz}$ show that the microphone arrangement provides an effective sidelobe control for the chosen grid. The point-spread function does not show any disturbing side lobes above $-10 \mathrm{~dB}$. For a decreased temperature of $100 \mathrm{~K}$, the spatial resolution improves. For the decreased speed of sound at lower temperatures [see Eq. (3)], the wavelengths become smaller for constant frequencies. Thus, the spatial resolution is increased, and the point-spread function is shown to be a function of the temperature.
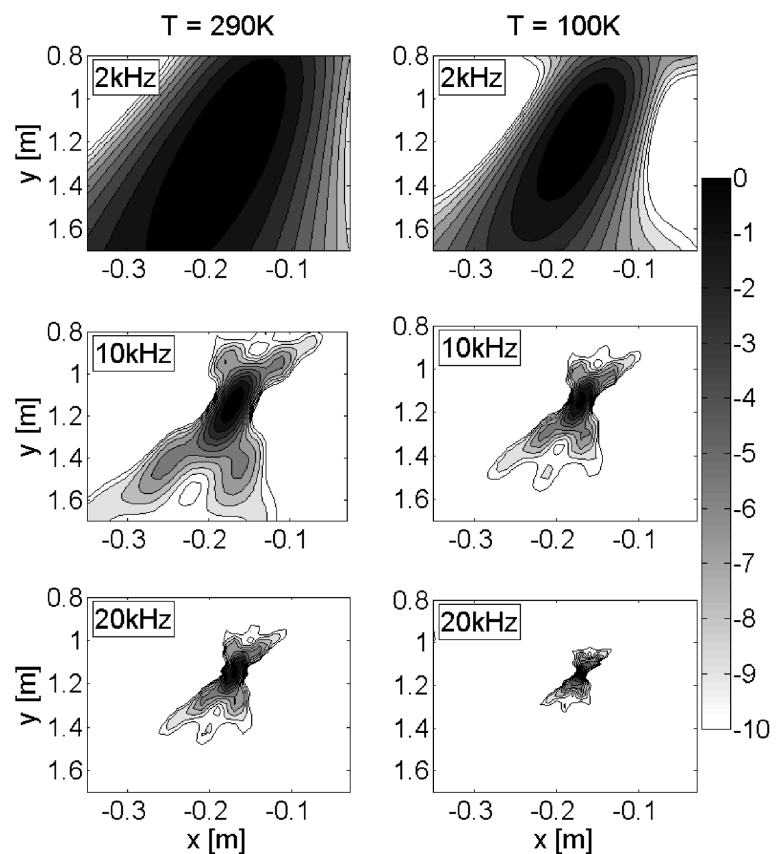

Fig. 11 Point-spread function (in $\mathrm{dB}$ ) of the microphone array at $f=2$, 10 , and $20 \mathrm{kHz}$, using the grid displayed in Fig. 10. The plots on the left are calculated for a temperature of $T=290 \mathrm{~K}$ and the plots on the right for a temperature of $T=100 \mathrm{~K}$.
For the beamforming procedure, a monopole source is assumed. The rod, however, is expected to radiate as a dipole source. Therefore, comparative numerical studies have been performed. The difference between the integrated sound power level of a simulated dipole and a simulated monopole, both radiating as a point source, were determined. The simulations were performed using the microphone and source positions of the experiment. For the adopted operational parameters of the experiment (density, speed of sound, and Mach number), this results in a maximum deviation of $0.3 \mathrm{~dB}$ for the sound power level tested in the range of $f<15 \mathrm{kHz}$.

\section{Spectral Representation}

In a following section, results at different temperatures will be compared. For the normalization, a reference monopole is required. The following shows the derivation of a reference monopole of equal sound power $P_{\text {sim }}$ for different temperatures. The propagated sound power of a monopole source under far-field conditions is given by

$$
P_{\text {sim }}=\oint_{S} \frac{1}{\rho c_{0}} p_{\mathrm{rms}}^{2} \mathrm{~d} S
$$

where, for the omnidirectional radiation of a monopole source, the surface integral is given by $\oint \mathrm{d} S=4 \pi r^{2}$. The rms value of the sound pressure is denoted by $p_{\text {rms. }}$. The sound pressure radiated by a monopole source of source strength $\hat{Q}$ is given by

$$
p(r, t)=\frac{\hat{Q}}{4 \pi r} e^{-j \omega\left(r / c_{0}-t\right)}
$$

where $r$ denotes the distance between the source and the receiver. While considering simple harmonics, the rms sound pressure of this monopole radiated in the far field leads to

$$
p_{\mathrm{rms}}=\sqrt{\frac{1}{2}} \frac{\hat{Q}}{4 \pi r}
$$

Together with Eq. (7), this yields to a source strength of $\hat{Q}=$ $\sqrt{P_{\text {sim }} \cdot 8 \pi \rho c_{0}}$. Thus, the sound pressure radiated by a monopole in the far field can be written as

$$
p_{\text {sim }}(r, t)=\frac{\sqrt{P_{\text {sim }} \cdot 8 \pi \rho c_{0}}}{4 \pi r} e^{-j \omega\left(r / c_{0}-t\right)}
$$

By using this equation, we get an expression for a monopole source where the sound power is always $P_{\text {sim }}$, independent of $\rho$ and $c_{0}$. The integrated sound power level of our measured data is then obtained by integrating over the whole grid region, normalized by a source map of the reference monopole situated at a known source position $[\underline{12}, \underline{13}]$ :

$$
P_{\exp }=\sum_{\mathbf{y}_{f}} \hat{S}_{z z, \exp }\left(\mathbf{y}_{f}\right) \times \frac{P_{\text {sim }}}{\sum_{\mathbf{y}_{f}} \hat{S}_{z z, \operatorname{sim}}\left(\mathbf{y}_{f}\right)}
$$

In this equation, $P_{\text {sim }}$ is the absolute sound power of the simulated monopole, which leads to the source auto powers $\hat{S}_{z z \text {,im }}\left(\mathbf{y}_{f}\right)$ for every point $\mathbf{y}_{f}$ on the scan grid. Reference maps for each Mach number and temperature were calculated to obtain the integrated source power $P_{\text {exp }}$.

\section{Contraction}

The material of the array fairing will alter its volume in response to a change in temperature. A variation in dimensions will lead to a temperature-dependent array pattern. As described in the measurement setup, the fairing assembly was rigidly fixed at only the array center. This results in a relative change of each microphone position in reference to the center microphone, which leads to a defocusing of source locations at focused grid points. Thus, the contraction has to be taken into account. The fairing was made of an aluminum-based alloy, namely, Weldural. Information about the contraction behavior is obtained from work carried out by Rhodes et al. [14], who 
investigated the comparable alloy AL 2219 T81. The displacement values found in their work have been applied to the array analysis here.

In the frequency range up to $f=20 \mathrm{kHz}$, the results obtained in this work were not significantly affected by the alteration of the microphone positions due to contraction. The distance between the most exterior microphones on the array is $1.04 \mathrm{~m}$, which causes a maximum contraction of $3.6 \mathrm{~mm}$ for $T=100 \mathrm{~K}$. At a temperature of $100 \mathrm{~K}$ and a frequency of $f=20 \mathrm{kHz}$, the associated wavelength is $10.3 \mathrm{~mm}$, which is larger when compared with the contraction. Nevertheless, the displacement should be adopted if measurements at higher frequencies are performed.

\section{Predictions}

The evaluation of the measurements leads to a data set of radiated sound powers that depend on $\rho, u_{\infty}$, and $c_{0}$. To assess the obtained data, they will be compared with results from a noise prediction model, which is based on noise radiation from a circular cylinder in a homogeneous flow field:

$$
\overline{p_{\text {pred }}^{2}(r)}=\frac{\rho^{2}}{16 c_{0}^{2}} \frac{\cos ^{2}(\theta)}{r^{2}} C_{l^{\prime}}^{2} u_{\infty}^{6} S t^{2} \Lambda_{d} l
$$

where $r$ denotes the distance from the source to the receiver and $\theta$ the angle normal to the flow direction: This has been shown by Phillips [6] and used to process experimental data by Fujita et al. [7] and Hutcheson and Brooks [8]. The resulting sound power can be expressed in the form

$$
P_{\text {pred }}=\oint_{S} \frac{1}{\rho c_{0}} \overline{p_{\text {pred }}^{2}(r)} \mathrm{d} S
$$

where a surface element is given by $\mathrm{d} S=r^{2} \sin (\theta) \mathrm{d} \theta \mathrm{d} \phi$. With the assumption of a constant diameter $d$ and length $l$, the qualitative radiated sound power simplifies to

$$
P_{\text {pred }} \propto \rho c_{0}^{-3} u_{\infty}^{6} S t^{2} C_{l^{\prime}}^{2} \Lambda_{d}
$$

The resulting formulation includes the classical dipole assumption with a sixth-order $u_{\infty}$ dependency. The dependence of the state of the surrounding fluid on temperature has to be taken into account. Important quantities are the density $\rho$ and the speed of sound $c_{0}$. They can be derived from basic thermodynamics. Furthermore, the radiated sound power is a function of the fluctuating lift coefficient normalized by cylinder length $C_{l^{\prime}}$, the correlation length $\Lambda_{d}$ normalized by cylinder diameter, and the Strouhal number $S t$. These quantities depend on the Reynolds number.

These data have not been separately determined in the present study, so that empirical data from literature [15-18] have been used, as summarized in Fig. 12. The presented functions are based on empirical formulations obtained from various experiments performed at a wide range of velocities and cylinder diameters. Considering Eq. (12), the changes of the variables are equivalent to 14,5 , and $1 \mathrm{~dB}$ within this Reynolds number range. For more information about the underlying database, the comprehensive work of Norberg [15] is recommended as a good reading.

\section{Experimental Results and Discussion}

\section{Source Maps}

The source maps were computed over the grid region shown in Fig. 10, using the standard beamforming method described previousty. Figures 13 and 14 show the source maps for a Mach number of $M a=0.3$. Each individual map is plotted with a dynamic range of $10 \mathrm{~dB}$. Figure 13 shows the source map at $T=290 \mathrm{~K}$. The corresponding Reynolds number is $R e_{d}=1.7 \cdot 10^{4}$. It can be seen that the maximum source power measured in the third-octave band is $f_{3 \text { rdOct. }}=8 \mathrm{kHz}$, which corresponds to a predicted Strouhal frequency of $f_{S t} \approx 7.7 \mathrm{kHz}$. At frequencies lower than this thirdoctave frequency band, no significant source position can be identified, as opposed to higher frequencies, where it is clearly

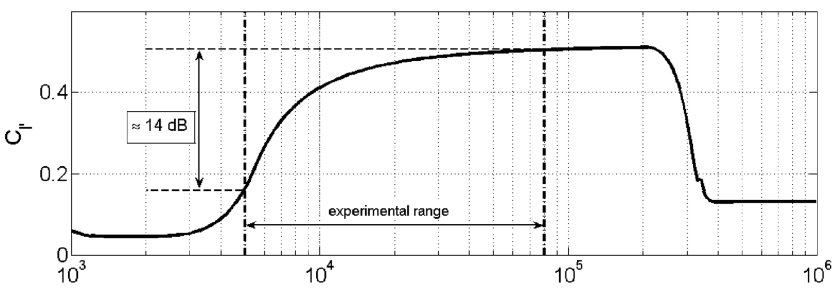

a)

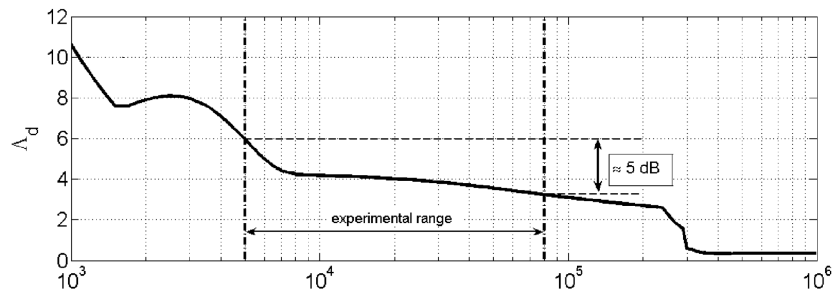

b)

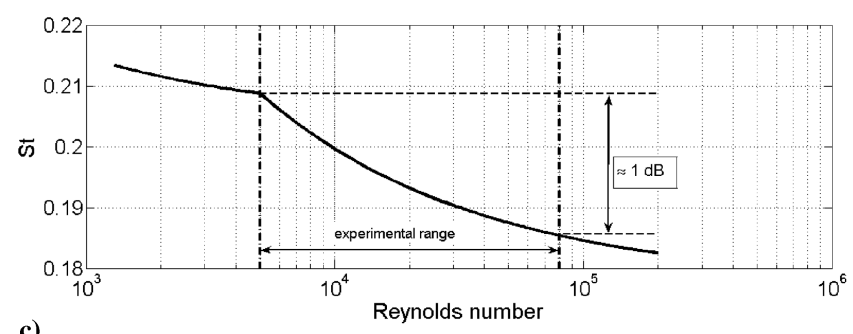

Fig. 12 Reynolds numbers vs a) fluctuating lift coefficient $C_{l^{\prime}}$, b) normalized spanwise correlation length (data taken from Norberg [15]), and b) Strouhal number [18]. Vertical lines show the range of Reynolds numbers used in the present work.

visible. This is probably related to flow-induced broadband noise from the cylinder.

Figure 14 shows the source map at $T=100 \mathrm{~K}$. The corresponding Reynolds number is $R e_{d}=7.7 \cdot 10^{4}$. The third-octave band with the maximum source power has now been shifted to a lower frequency. At a constant Mach number and a temperature-dependent reduced speed of sound, the resulting mean flow velocity must also be reduced; this leads to a decreased frequency. At an approximately constant Strouhal number, the resulting Strouhal frequency is,
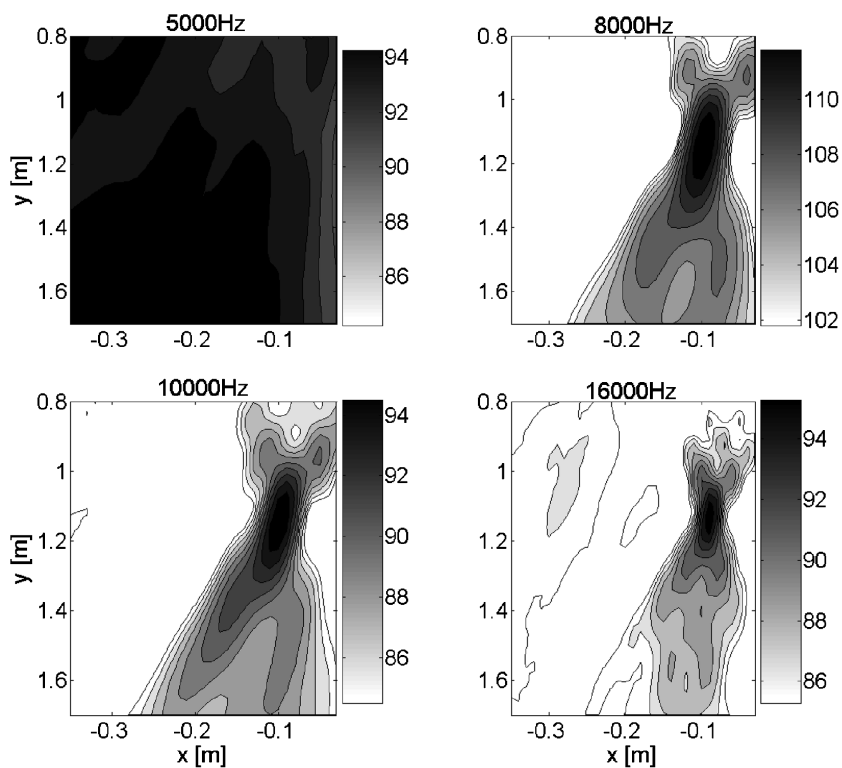

Fig. 13 Source maps for the radiated noise from the cylinder in a flow at $T=290 \mathrm{~K}$ and $M a=0.3$. The corresponding Reynolds number is $R e_{d}=1.7 \cdot 10^{4}$. The range of the color scales is always $10 \mathrm{~dB}$, the maximum level is that appropriate for each frequency band. 

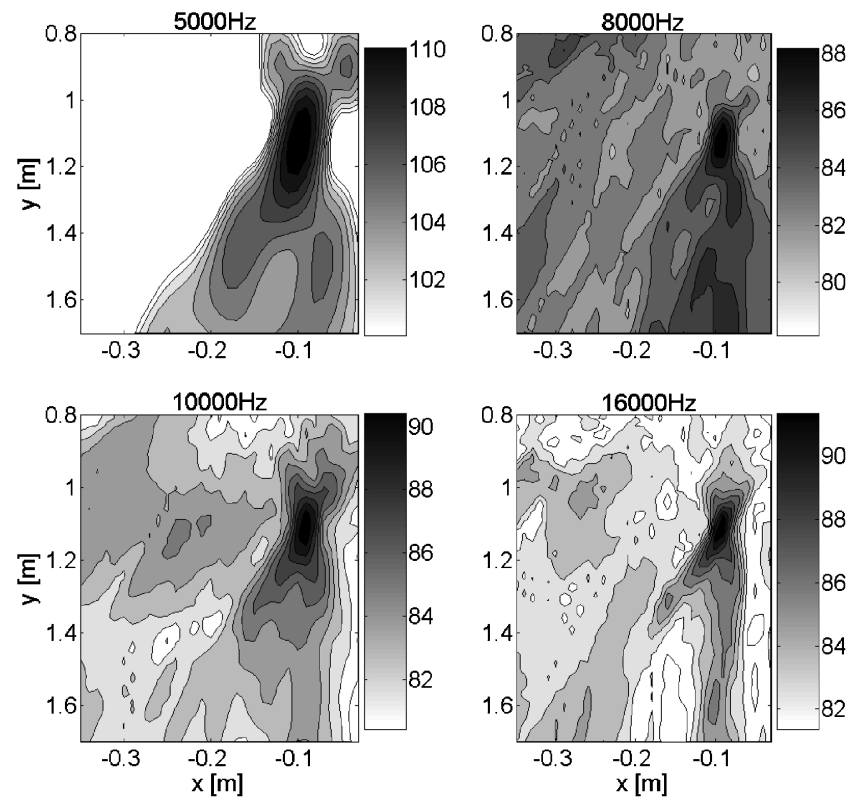

Fig. 14 Source maps for the radiated noise from the cylinder in flow at $T=100 \mathrm{~K}$ and $M a=0.3$. The corresponding Reynolds number is $R e_{d}=7.7 \cdot 10^{4}$. The range of the color scales is always $10 \mathrm{~dB}$, the maximum level is that appropriate for each frequency band.

therefore, at $f_{S t} \approx 4.4 \mathrm{kHz}$. Compared with a temperature of $290 \mathrm{~K}$, the spatial resolution has been improved, as shown of Fig. 11. In addition, the source position here can also be clearly identified in the higher frequency bands. Above a frequency of $f_{3 \text { rdOct. }}=8 \mathrm{kHz}$, the signal-to-noise ratio is significantly reduced when compared with the case of $290 \mathrm{~K}$. This is probably related to an increased background noise level caused by the wind tunnel, which was not measured.

\section{Integrated Source Power}

The source maps were further processed using the source power integration method described previously. Figure 15 shows the sound power level for different Mach numbers at $T=\overline{29} 0 \mathrm{~K}$, and Fig. 16 shows the sound power level for different Mach numbers at $T=$ $100 \mathrm{~K}$ as a function of both the frequency and the Strouhal number. Note that the frequency ranges for the two plots are different, so that only the first peak can be seen in the Strouhal number plots. Each spectrum shows a peak at the rod's vortex shedding frequency. For higher frequencies, smaller peaks arising from higher harmonics can
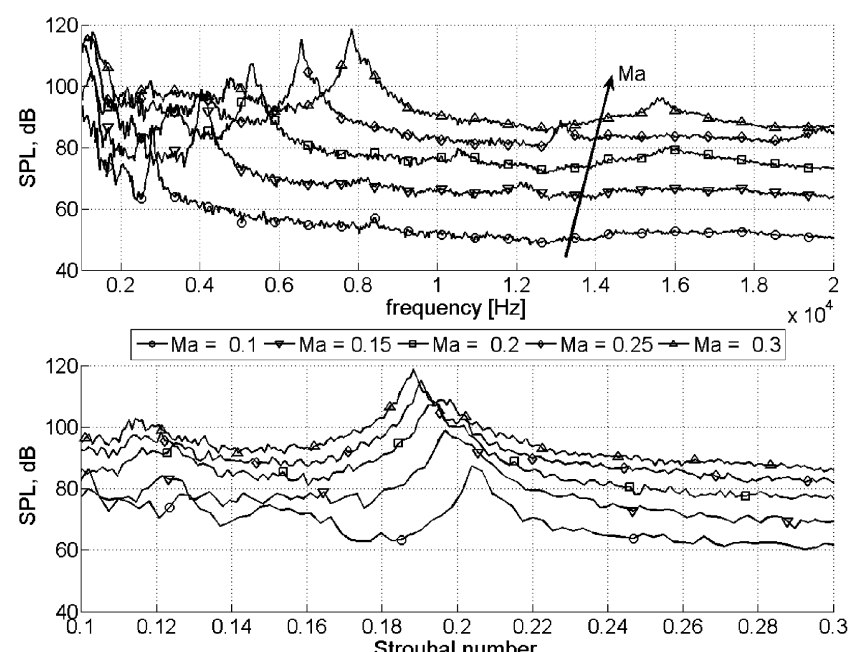

Fig. 15 Sound power level for several Mach numbers at $T=290 \mathrm{~K}$. Displayed is the sound power level $\left(\mathrm{dB}, 1 \cdot 10^{-12} \mathrm{~W}\right)$ versus frequency (top) and versus frequency normalized with freestream velocity and cylinder diameter (i.e., the Strouhal number) (below).
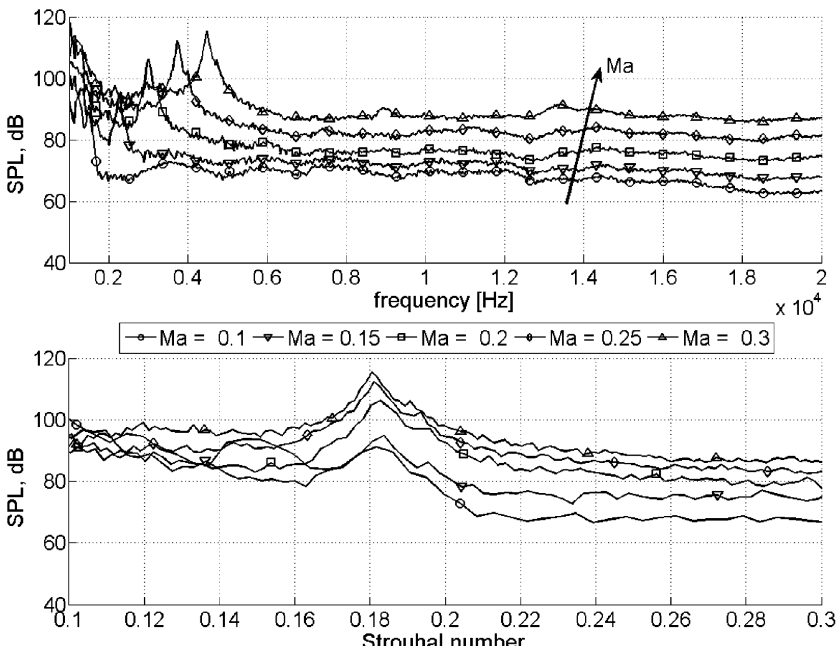

Fig. 16 Sound power level for several Mach numbers at $T=100 \mathrm{~K}$. Displayed is the sound power level $\left(\mathrm{dB}, 1 \cdot 10^{-12} \mathrm{~W}\right)$ versus frequency (top) and versus frequency normalized with freestream velocity and cylinder diameter (i.e., the Strouhal number) (below).

also be identified. A comparison of the plots at the two temperatures shows a downward frequency shift at $100 \mathrm{~K}$, which is due to the lower freestream velocity $u_{\infty}$. At $T=290 \mathrm{~K}$, the peak in sound power shifts to lower Strouhal numbers as the Mach number increases, where the Reynolds number also increases. On the other hand, at $T=100 \mathrm{~K}$, the peak is hardly shifted at the various Mach numbers. This corresponds to the well-known Strouhal-Reynolds number relationship in the Reynolds number region obtained in this work. Figure 17 compares all measured data with those obtained using the model by Fey et al. [18]. The measured Strouhal number lies within the error margin proposed by the model and is in good agreement. However, with increasing Reynolds numbers, the measured data tend to have lower values than predicted by the model. At higher Mach numbers and decreased temperatures, the turbulence level in the KKK is increased [5], which can influence the cylinder wake. The systematic deviation can also be caused by an unknown inhomogeneous flowfield in the test section of the wind tunnel and thus, perhaps, by an underpredicted flow velocity at the cylinder position. In addition, the influence of compressibility effects at higher Mach numbers cannot be excluded.

The relative bandwidth of the peaks in the Strouhal number plots seems to be approximately constant. Therefore, we assume that the

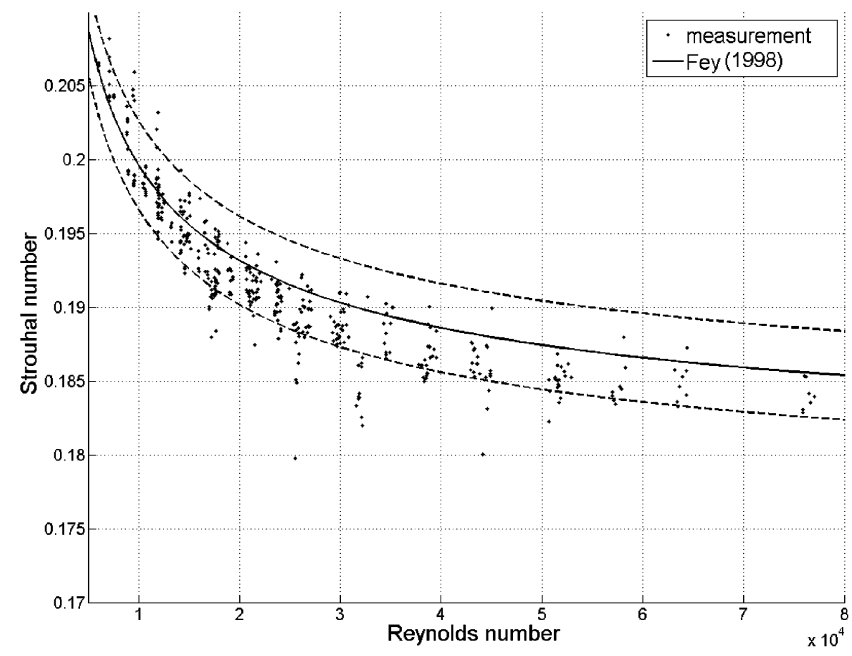

Fig. 17 Strouhal number versus Reynolds number. Displayed is the Strouhal number of the peak level for each measurement (dots) compared with the proposed law (solid line) and its estimated error bands (dashes) for the Strouhal-Reynolds number relationship by Fey et al. [18]. 

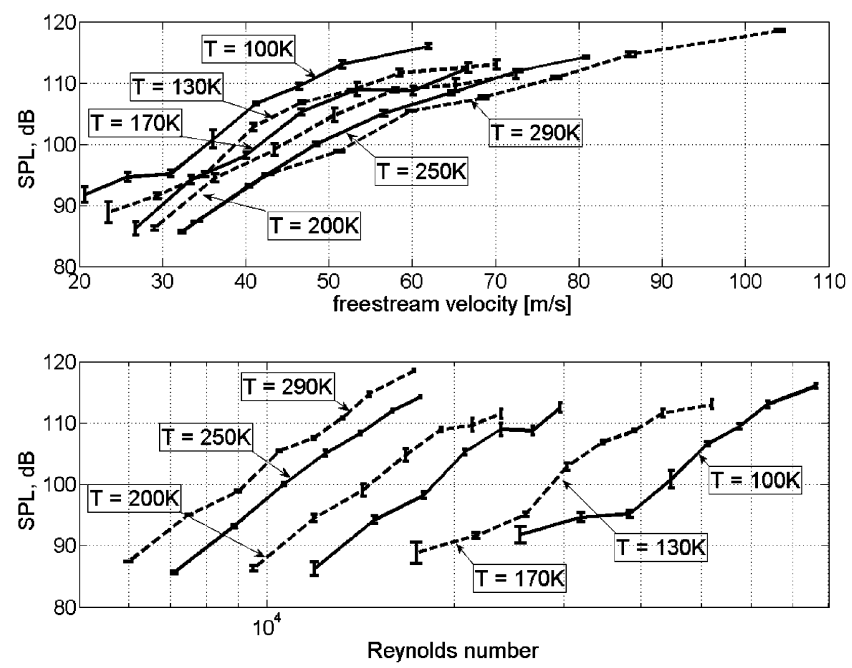

Fig. 18 Peak level of the measured sound power plotted versus freestream velocity (top) and the Reynolds number (below). The standard deviation ( $\mathrm{dB}$ ) of the measured data is indicated by the error bars.

peak level gives a good indication of the quantitative tonal component of the radiated sound power. In terms of the following analysis, the peak level will be used. Figure 18 depicts the peak level of the sound power level spectra versus the freestream velocity (top) and versus the Reynolds number (below). From repeated measurements at each freestream velocity, an indication of the scatter of the measured data could be derived and is indicated by the error bars. It should be noted that, because of the measurement sequence (see Table 1), more measurements were repeated at temperatures in the range of $130 \mathrm{~K}<T<200 \mathrm{~K}$, whereas at $T=290 \mathrm{~K}$ and $T=100 \mathrm{~K}$, only a few data values were recorded. The highest scatter occurs at low Mach numbers, where the spatial resolution of the microphone array, and probably the signal-to-noise ratio of the measured data, is lower than for higher Mach numbers.

The major deviations occur in specific regions. For example, at a temperature of $T=100 \mathrm{~K}$ and Mach numbers of $M a=0.15$ and $M a=0.2$, a systematic deviation can be observed. Because of the fact that each measurement point was reached by approaching the Mach number from below, this could possibly be related to a transition for a Reynolds number around $R e_{d}=4 \cdot 10^{5}$. According to Zdravkovich [19], a further increase in this Reynolds number range results in a transition to the so-called supercritical regime, where (probably) a hysteresis effect may occur. A similar observation can be made for $R e_{d} \approx 2.5 \cdot 10^{2}$ at temperatures $T=130 \mathrm{~K}$ and $T=170 \mathrm{~K}$. In addition, the temperature calibration discussed earlier contributes an uncertainty of $1.5 \mathrm{~dB}$ in this frequency range.

\section{Dimensional Analysis}

A dimensional analysis was carried out in order to study the influence of the varied physical quantities on the radiated sound power. For a simple approach, the following quantities were taken into account:

$$
P=f\left(u_{\infty}, \rho, d, c\right)
$$

From the Buckingham $\pi$ theorem, we assume the following relation between the physical quantities:

$$
P \propto u_{\infty}^{n_{1}} \rho^{n_{2}} c^{n_{3}} d^{n_{4}}
$$

With the basic units of the quantities, we can find

$$
M L^{2} T^{-3}=\left(L T^{-1}\right)^{n_{1}}\left(M L^{-3}\right)^{n_{2}}\left(L T^{-1}\right)^{n_{3}}(L)^{n_{4}}
$$

In this equation, $M, L$, and $T$ denote the basic units mass, length, and time. This leads to the following system of equation:

$$
1=n_{1} ; \quad 2=n_{1}-3 n_{2}+n_{3}+n_{4} ; \quad-3=-n_{1}-n_{3}
$$

From this linear system of equations, it follows that

$$
P \propto u_{\infty}^{n_{1}} \rho^{1} c^{3-n_{1}} d^{2}
$$

Since the freestream velocity and the speed of sound have the same dimensions, the equation cannot be determined unambiguously. To overcome this problem, Eq. (16) was compared with all measured data to determine the minimum residual. This approach shows the best fit for a model with $u_{\infty}$ to the power of 6.62 and $c$ to the power of -3.62 :

$$
P \propto u_{\infty}^{6.62} \rho^{1} c^{-3.62} d^{2}
$$

The result differs from the classical dipole assumption with a sixthorder $u_{\infty}$ dependency, as shown by Phillips [6]. In spite of that, this model is a valid possibility for the comparison. In previous publications, various exponents for different Reynolds number regimes from $u_{\infty}^{4}$ (Gerrard [20]) to $u^{7.6}$ (Holle [21]) can be found. Figure 19 shows comparisons between the measured sound power and the dimensional analysis, using Eq. (17) versus the freestream velocity in the upper plot and versus the Reynolds number in the lower plot. The measured data are normalized to the sound power level at a Mach number $M a=0.1$ and temperature $T=290 \mathrm{~K}$. The comparison shows a good agreement with a mean absolute deviation of $1.3 \mathrm{~dB}(\mathrm{rms})$ and maximum absolute deviation of approximately $6.3 \mathrm{~dB}$ in the whole Mach-temperature range.

\section{Comparison of Measured Data and Predicted Values}

Following on from the observations made in the previous section [see Eq. (12)], Fig. 20 shows the comparison between the prediction model and the measured data. The measured and predicted data are normalized to the sound power level at a Mach number $M a=0.1$ and temperature $T=290 \mathrm{~K}$. For the prediction model, values of $S t$, $C_{l^{\prime}}$, and $\Lambda_{d}$ were used from the empirical formulations shown in Fig. 12, provided by Norberg [15] and Fey et al. [18]. The comparison shows a very good agreement. The mean deviation is $1.3 \mathrm{~dB}(\mathrm{rms})$, and the maximum deviation is approximately $4.2 \mathrm{~dB}$.

Deviations are attributed to uncertainties in both the underlying database $[\underline{15}, \underline{18}]$ for the prediction model and in the measured data. Most importantly, uncertainties in the measured data are 1) temperature-dependent amplitude calibration $( \pm 1.5 \mathrm{~dB}), 2)$ the possible existence of an inhomogeneous flowfield in the test section, and 3) the temperature and velocity dependent turbulence level in the test section
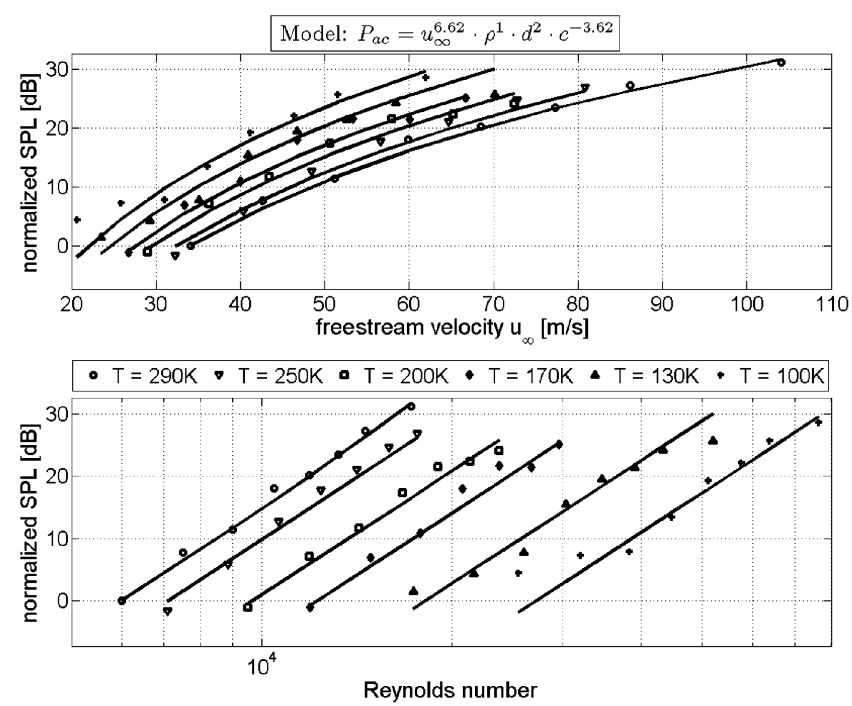

Fig. 19 Comparison of the results obtained from the dimensional analysis [Eq. (17), solid lines] with the measured data. Shown is the normalized sound power level at various temperatures plotted versus the freestream velocity (top) and versus the Reynolds number (bottom). 

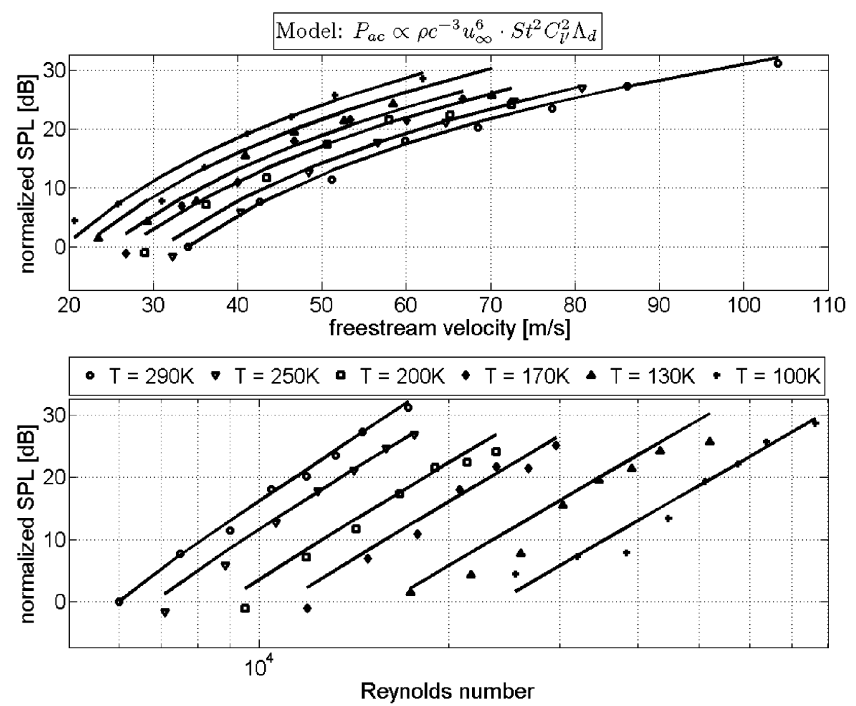

Fig. 20 Comparison of the results obtained from the prediction model [Eq. (12), solid lines] with the measured data. Shown is the normalized sound power level at various temperatures plotted versus the freestream velocity (top) and versus the Reynolds number (bottom).

Also, simplifications regarding the delay-and-sum beamforming algorithm, such as the discussed monopole assumption with an estimated error of $0.3 \mathrm{~dB}$ for the cylinder, contribute an uncertainty to the analyzed data. Unconsidered effects, like the coherence loss due to the boundary layer on the array and the convective amplification, also contribute an uncertainty to the analyzed data.

In addition, there are effects that are unaccounted for in the model (and the underlying database for $C_{l^{\prime}}, \Lambda_{d}$, and $S t$ ): 1) compressibility effects, 2) hysteresis effects at transition changes, and 3) scatter of the underlying database.

These are mainly thought to be responsible for the differences between the predicted and measured sound powers but cannot, however, be further quantified. Despite the empirical database and the previously discussed uncertainties in the measured data, the comparison still shows good agreement.

\section{Conclusions}

A linear microphone array for cryogenic application has been developed and constructed. Electret microphones, electronic equipment, and fairing materials have been successfully tested under cryogenic conditions and have shown long-term stability. It should be noted that the electret microphones and the self-built preamplifiers could withstand temperatures down to $100 \mathrm{~K}$, subject to the condition that the temperature gradient in cooling is not too high (approximately up to $50 \mathrm{~K} / \mathrm{h}$ ).

Subsequently, acoustic array measurements were performed in a cryogenic wind tunnel for various temperatures in the range $100 \mathrm{~K}<T<290 \mathrm{~K}$, using a single-rod configuration. The Mach and Reynolds (based on cylinder diameter $d=2.5 \mathrm{~mm}$ ) numbers were in the range 0.1 to 0.3 and $5 \cdot 10^{3}$ to $8 \cdot 10^{4}$, respectively. The experiments demonstrated the technical feasibility of aeroacoustic array measurements at these low temperatures. When carrying out microphone-array measurements in a cryogenic wind tunnel, the following should be considered.

1) The first consideration is the restricted access to the test section, especially during operation of the wind tunnel.

2) The second consideration is the temperature-dependent thermal expansion/contraction of the array fairing material.

3) The third consideration is the secure mounting (cryowithstanding screws, etc.), whereby special attention needs to be paid to the temperature-dependent contraction.

A systematic study of Reynolds and Mach-number effects on the radiated noise of a single-rod configuration has also been carried out. The measured sound power results showed a good agreement with a commonly used prediction model. The existence of a Reynolds number dependency of the measured and predicted sound power has been demonstrated. For the beamforming analysis of the measured data, the following should be considered.

1) The first consideration is the relative changes of the microphone positions because of the thermal contraction of the array fairing.

2. The second consideration is the change in the speed of sound due to the different temperatures.

At present, a large array for cryogenic application, based on the test array, has been constructed. Measurements on a Dornier DO-728 half-model will be performed in a wide range of Mach numbers and temperatures.

To predict full-scale airframe noise based on small-scale model measurements via the phased microphone-array measurement technique, future work should be focussed on acquiring aeroacoustic data in an environment that is both pressurized and cryogenic.

\section{Acknowledgments}

The authors would like to express their sincere appreciation to all those who have contributed to this paper in the form of technical or other support. For the technical support, we thank the staff of the Kryo-Kanal Köln for helpful advice concerning the installation of the acoustic equipment in the test section of the wind tunnel. We would also like to thank our DLR colleagues from the Department of Experimental Methods who advised and assisted us during this research. That includes, especially, the Acoustic Group and last, but not least, the TSP Group for their helpful initiation into cryogenic measurement techniques.

\section{References}

[1] Koop, L., Sijtsma, P., and Oerlemans, S., "Noise Source Localization in Closed Test Sections with Microphone Arrays," 1st CEAS European Air and Space Conference [CD-ROM], CEAS-2007-333, Deutsche Gesellschaft fr Luft- und Raumfarht, Bonn, 2007, pp. 1-10.

[2] Hayes, J. A., Horne, W. C., Jaeger, S. M., and Soderman, P. T., "Measurement of Reynolds Number Effect on Airframe Noise in the 12Foot Pressure Wind Tunnel," 5th AIAA/CEAS Aeroacoustics Conference and Exhibit, AIAA Paper 1999-1959, 1999.

[3] Stoker, R. W., Gutierrez, R., Larssen, J. V., Underbrink, J. R., Gatlin, G. M., and Spells, C., "High Reynolds Number Aeroacoustic Testing in NASA's National Transonic Facility (NTF)," 46th AIAA Aerospace Science Meeting and Exhibit, AIAA Paper 2008-838, 2008.

[4] Koop, L., and Ehrenfried, K., "Microphone-Array Processing for WindTunnel Measurements with Strong Background Noise," 14th AIAA/ CEAS Aeroacoustics Conference, AIAA Paper 2008-2907, 2008.

[5] Viehweger, G., Rebstock, R., Stahl, B., Wichmann, K., Becker, W., Kronen, R., and Distelrath, D., "Der Kryo-Kanal Koeln (KKK) der DLR (Stand 1992)," DLR, Message 93-10, 1993.

[6] Phillips, O. M., "The Intensity of Aeolian Tones," Journal of Fluid Mechanics, Vol. 1, No. 6, 1956, pp. 607-624. doi:10.1017/S0022112056000408

[7] Fujita, H., Suzuki, H., Sagawa, A., and Takaishi, T., "The Aeolian Tone Characteristics of a Circular Cylinder in High Reynolds Number Flow," 5th AIAA/CEAS Aeroacoustics Conference, AIAA Paper 1999-1849, 1999.

[8] Hutcheson, F., and Brooks, T., "Noise Radiation from Single and Multiple Rods Configurations," 12th AIAA/CEAS Aeroacoustics Conference, AIAA Paper 2006-2629, 2006.

[9] Sutherland, W., "The Viscosity of Gases and Molecular Force," Philosophical Magazine Series 5, Vol. 36, No. 223, 1893, pp. 507-531.

[10] Hilsenrath, J., Beckett, C. W., Benedict, W. S., Fano, L., Hodge, H. J., Masi, J. F., Nuttall, R. L., Touloukian, Y. S., and Woolley, H. W., Tables of Thermal Properties of Gases, National Bureau of Standards, Circular 564, Washington, D. C., 1955.

[11] Johnson, D., and Dudgeon, D., Array Signal Processing: Concepts and Techniques, Prentice-Hall Signal Processing Series, Prentice-Hall, Upper Saddle River, NJ, 1993.

[12] Brooks, T., and Humphreys, W., "Effect of Directional Array Size on the Measurement of Airframe Noise Components," 5th AIAA/CEAS Aeroacoustics Conference, AIAA Paper 1999-1958, 1999.

[13] Oerlemanns, S., Broersma, L. S. P., "Quantification of Airframe Noise Using Microphone Arrays in Open and Closed Wind Tunnels," International Journal of Aeroacoustics, Vol. 6, No. 4, 2007, pp. 309333. 
doi: $10.1260 / 147547207783359440$

[14] Rhodes, B. L., Moeller, C. E., Hopkins, V., and Marx, T., "Thermal Expansion of Several Technical Metals from -255 to 300C," Advances in Cryogenic Engineering, Vol. 8, Plenum Press, New York, August 1962, pp. 278-286.

[15] Norberg, C., "Fluctuating Lift on a Circular Cylinder: Review and New Measurements," Journal of Fluids and Structures, Vol. 17, No. 1, 2003, pp. $57-96$. doi:10.1016/S0889-9746(02)00099-3

[16] Fung, Y. C., "Fluctuating Lift and Drag Acting on a Cylinder in a Flow at Supercritical Reynolds Numbers," Journal of the Aero/Space Sciences, Vol. 27, No. 11, 1960, pp. 801-814.

[17] Leehey, P., and Hanson, C. E., "Aeolian Tones Associated with Resonant Vibration," Journal of Sound and Vibration, Vol. 13, No. 4, 1970, pp. 465-483.

doi:10.1016/S0022-460X(70)80052-9
[18] Fey, U., Konig, M., and Eckelmann, H., "A New Strouhal-Reynoldsnumber Relationship for the Circular Cylinder in the Range $47<R e<2 \cdot 10^{5}$," Physics of Fluids, Vol. 10, No. 7, 1998, pp. 1547-1549. doi:10.1063/1.869675

[19] Zdravkovich, M. M. (ed.), Flow Around Circular Cylinders, Vol. 1, Oxford Univ. Press, Oxford, England, U.K., 1997.

[20] Gerrard, J. H., "Measurements of the Sound from Circular Cylinders in an Air Stream," Proceedings of the Physical Society, London, Section B, Vol. 68, No. 7, July 1955, pp. 453-461. doi:10.1088/0370-1301/68/7/307

[21] Holle, W., "Frequenz- und Schallstärkemessungen an Hiebtönen," Akustische Zeitschrift, Vol. 6, No. 3, 1938, pp. 321-331.

E. Gutmark Associate Editor 